\title{
A purple patch for a power problem
}

\author{
Rhys Thomas, MBBS, FANZCA (i)
}

Received: 20 November 2018/Revised: 22 November 2018/ Accepted: 22 November 2018/Published online: 4 December 2018

(c) Canadian Anesthesiologists' Society 2018

\section{To the Editor,}

We would like to suggest a potential improvement to Dr. Pysyk's idea of labelling the power cord of the anesthetic machine to warn against accidental disconnection. ${ }^{1}$ This letter was brought to our attention via a near-miss report made through our local anesthesia safety monitoring project. The anesthesiologist involved described "carefully trac[ing] the electrical cord of a theatre appliance back to the panel of outlets on the boom... [but] still manag[ing] to unplug the anesthetic machine." Included in the report was a copy of Dr. Pysyk's article ${ }^{1}$ and the suggestion that we could implement a similar solution of power cord labelling.

Following discussions in both our local Human Factors and Equipment Committees, we implemented a variation on the labelling approach by changing the cords on our anesthetic machines from the orange colour shared by all our other equipment, to uniquely purple coloured cords.
This has the advantage of identifying the cable along its entire course and from every viewing angle. Furthermore, it is not susceptible to fading or becoming detached in the same way a label is. It does, however, require the ability to distinguish between the orange and purple colours used, and this may be impaired by factors such as lighting conditions, use of protective eyewear (e.g., laser cases), or colour vision deficiency in staff.

A further safeguard to consider would be combining colour coding and labelling. Alternatively, the addition of a "lock-in forcing function" within the power cable attachment mechanism might also help prevent accidental disconnections, though an engineered solution such as that would be a much larger undertaking compared with the relatively inexpensive and simple solution that we implemented. The new cables cost $\$ 9.11$ AUD each (ETD Pty Ltd, Chipping North, NSW, Australia) and replacement took approximately five minutes per machine

Figure The image on the left shows the original situation, where all operating room cords were orange and the anesthetic machine was inadvertently unplugged. The image on the right is after the anesthetic machine cord was changed to a purple one making it more distinguishable and less likely to be unintentionally disconnected

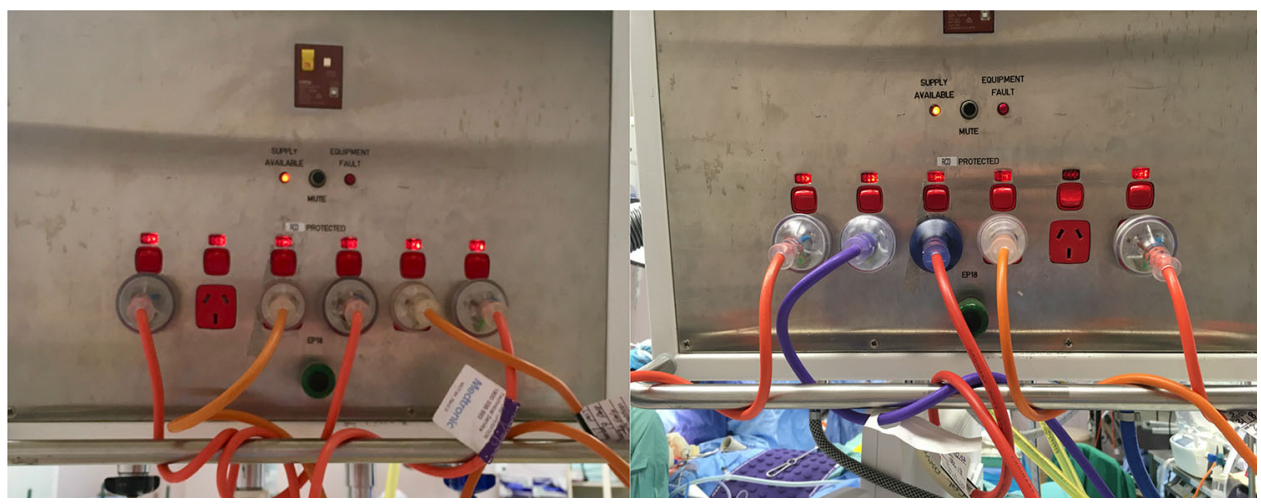

R. Thomas, MBBS, FANZCA ( $\square)$

John Hunter Hospital, New Lambton Heights, Australia 
(Aisys $\mathrm{CS}^{2}$ Carestation, GE Healthcare, Madison, WI, USA).

Our experience mirrors that of Dr. Pysyk in highlighting the importance of near-miss reporting systems, ${ }^{2}$ and the value of encouraging local responses to provide effective interventions for latent safety threats once they are identified.

We would also add that this risk from look-a-like power cords is increasing as the amount of electrical equipment used in theatres continues to increase. We suggest considering an international standard for labelling and colour coding of cables used to power critical equipment in hospitals to help reduce this risk. A starting point could be for anesthesiology professional bodies to include in their equipment standards that anesthetic machines be powered via purple electrical cords.
Conflicts of interest None declared.

Editorial responsibility This submission was handled by Dr. Hilary P. Grocott, Editor-in-Chief, Canadian Journal of Anesthesia.

\section{References}

1. Pysyk $C L$. Risk of look-a-like equipment in anesthesiology: it's not just medications. Can J Anesth 2017; 64: 1291-2.

2. Beattie WS, Culwick MD, Grocott HP. Canadian Anesthesia Incident Reporting System (CAIRS): The Canadian Anesthesiologists' Society's National Patient Safety Initiative. Can J Anesth 2018; 65: 749-56. 